\title{
INFLUÊNCIA DO ESTATUTO POSICIONAL SOBRE O COMPORTA- MENTO TÁTICO DE JOGADORES DE FUTEBOL
}

\author{
Roberto Nascimento Braga da Silva \\ Universidade Estadual Paulista, Rio Claro, São Paulo, Brasil \\ Israel Teoldo \\ Universidade Federal de Viçosa, Viçosa, Minas Gerais, Brasil \\ Davi Correia da Silva \\ Universidade Federal de Viçosa, Viçosa, Minas Gerais, Brasil \\ Lilian Aparecida Ferreira \\ Universidade Estadual Paulista, Bauru, São Paulo, Brasil \\ Júlio Wilson Dos-Santos \\ Universidade Estadual Paulista, Bauru, São Paulo, Brasil
}

\begin{abstract}
Resumo
Este estudo comparou o comportamento tático de jogadores de futebol da categoria Sub-15, de acordo com o estatuto posicional. Vinte e cinco jogadores de dois clubes portugueses foram avaliados através do Sistema de Avaliação Tática no Futebol. Utilizou-se estatística descritiva e o teste Qui-quadrado $\left(\chi^{2}\right)$, com o nível de significância de $p<0,05$. Os resultados apresentaram diferença significativa nas variáveis: Unidade ofensiva, Contenção e Concentração (Defensores); Mobilidade (Meio-campistas); Ações táticas ofensivas no meio de campo defensivo (Defensores); Cometer faltas, ceder lateral ou escanteio (Meio-campistas e Atacantes); Continuar sem a posse de bola (Defensores). Conclui-se que o comportamento tático dos jogadores apresentou níveis de especialização nas suas posições.
\end{abstract}

Palavras-chave: Avaliação Tática. Jogos Reduzidos e Condicionados. Tática.

\section{INFLUENCE OF THE POSITIONAL ROLE ON THE TACTICAL ACTIONS OF SOCCER PLAYERS}

\begin{abstract}
This study compared the tactical behavior of U-15 soccer players according to the positional role. Twenty-five players from two Portuguese clubs were evaluated through the System of Tactical Assessment in Soccer (FUT-SAT). Descriptive statistics and chi-square test $\left(\chi^{2}\right)$ were used, with significance level of $\mathrm{p}<0.05$. Results displayed significant statistical differences for the following variables: Offensive Unit, Delay and Concentration (Defenders); Depth Mobility (Midfielders); Offensive tactical actions in defensive midfield (Defenders); Commit a foul, give away a corner or throw-in (Midfielders and Forwards); Ball possession of the opponent (Defenders). We conclude that the tactical behavior of the players presented levels of specialization in their positions.
\end{abstract}

Keywords: Tactical Evaluations. Small-sided and Conditioned Games. Tactical. 


\section{INFLUENCIA DEL RANGO POSICIONAL SOBRE EL COMPORTAMIENTO TÁCTICO DE LOS JUGADORES DE FÚTBOL}

Resumen: Este estudio comparó el comportamiento táctico de los jugadores de fútbol de la categoría Sub-15 en relación al rango posicional. Evaluamos a 25 jugadores de dos clubes Portugueses por medio del Sistema de Evaluación de la Táctica en Fútbol (FUT-SAT). Usamos la estadística descriptiva y el test de Chi-cuadrado $\left(\chi^{2}\right)$, con elnivel de significancia de $\mathrm{p}<0,05$. Los resultados presentaron diferencia significativa en las variables: Unidad ofensiva, Contención y Concentración (Defensas); Movilidad (Mediocampistas); Acciones tácticas ofensivas en el medio de campo defensivo (Defensas); Cometer faltas, ceder un saque de banda o córner (Mediocampistas y Atacantes); continuar sin la posesión del balón (Defensas). Se concluyó que el comportamiento táctico de los jugadores presentó niveles de especialización en sus posiciones.

Palabras clave: Evaluación Táctica. Juegos Reducidos y Condicionados. Táctica.

\section{Introdução}

No Futebol, devido à incessante disputa dos jogadores e das equipes pelo espaço de jogo, os jogadores devem ser capazes de gerir esse espaço no intuito de gerar organização e equilíbrio nas ações da própria equipe e, simultaneamente, procurar desorganizar e desequilibrar a equipe adversária (GARGANTA; GRÉHAIGNE, 1999). De acordo com a literatura, a gestão do espaço de jogo decorre do posicionamento e da movimentação dos jogadores no campo de jogo (TEOLDO; GUILHERME; GARGANTA, 2015). Essa gestão é considerada fulcral da componente tática e, por isso, tem sido alvo de diversas investigações científicas (TEOLDO et al., 2011b; SANTOS et al., 2013; SILVA et al., 2014).

No que se refere às investigações científicas, em geral, essas investigações apontam que o comportamento e o desempenho tático dos jogadores são influenciados pelos constrangimentos do jogo (ex: tamanho do campo, superfície de campo e número de jogadores). Dessa maneira, em diferentes situações de jogo, os jogadores tendem a realizar determinadas ações táticas em detrimento de outras, o que modifica o comportamento e o desempenho inerentes às movimentações nas diferentes fases do jogo. Adicionalmente, outro fator que pode influenciar o comportamento tático dos jogadores é o estatuto posicional (defesa, meio-campo e ataque), pois a literatura revela que o estatuto posicional pode constranger as ações dos jogadores devido às características de cada posição (BAYER, 1994).

Considerando esse contexto referente ao estatuto posicional, alguns estudos no futebol profissional buscaram verificar a influência do estatuto posicional sobre os indicadores espaciais relativos ao desempenho sobre as ações com bola (JAMES; MELLALIEU; HOLLELY, 2002; TAYLOR; MELLALIEU; JAMES, 2005). Esses estudos indicaram que os comportamentos desempenhados pelos jogadores são característicos das posições que ocupam no campo. Desse modo, as prescrições de treinamento no futebol devem considerar os requisitos específicos das posições dos jogadores no intuito de torná-los capazes de cumprir suas dinâmicas táticas durante o jogo (DI SALVO et al., 2007).

Adicionalmente, outros estudos buscaram investigar a influência do estatuto posicional sobre o comportamento e o desempenho tático através dos jogos reduzidos e condicionados em diferentes categorias etárias (GONZAGA; GONÇALVES; TEOLDO, 2014; PADILHA; MORAES; TEOLDO, 2013). Dentre esses estudos, Padilha, Moraes e Teoldo (2013) encontraram que, na categoria Sub-13, os meio-campistas apresentaram melhor desempenho relacionado às movimentações que permitem à equipe atacar em unidade em relação aos atacan- 
tes. Por sua vez, Gonçalves, Rezende e Teoldo (2015) analisaram os jogadores da categoria Sub-17 e verificaram que os defensores e os meio-campistas apresentaram melhor desempenho relacionado às movimentações da fase ofensiva do jogo em detrimento do desempenho relacionado às movimentações da fase defensiva. Os estudos supracitados corroboram o fato de que o desempenho tático é influenciado pelo estatuto posicional e pela fase de jogo (ofensiva e defensiva).

Por outro lado, Gonzaga, Gonçalves e Teoldo (2014) investigaram a categoria Sub-15 e não encontraram diferenças no comportamento tático dos jogadores de diferentes posições em situação de jogo reduzido e condicionado. Os autores concluíram que esse resultado pode ser consequência da falta de especialização dos jogadores nas posições que exercem no jogo. Por conseguinte, Giacomini e Greco (2008) analisaram jogadores das categorias Sub-14, Sub15 e Sub-17 e encontraram que os meio-campistas possuem maior conhecimento tático processual divergente (que está relacionado à criatividade tática) em relação aos zagueiros. No entanto, o teste utilizado no estudo de Giacomini e Greco pode não expressar, em sua totalidade, as exigências e dinâmicas do jogo de futebol, uma vez que os jogadores são avaliados apenas nas movimentações sem bola e sem mudanças das fases de jogo.

Apesar de sua contribuição para o entendimento de como jogadores de diferentes posições se comportam, esses estudos ainda são incipientes, uma vez que os resultados apresentados não são conclusivos. Consequentemente, a análise do comportamento tático dos jogadores, de acordo com o estatuto posicional em diversos contextos, pode ter implicações para o processo de formação esportiva pela possibilidade de identificar padrões observáveis de comportamento em determinadas faixas etárias (GREHAIGNE; BOUTHIER; DAVID, 1997; SILVA et al., 2014). Portanto, o presente estudo teve como objetivo comparar o comportamento tático de jogadores de futebol da categoria Sub-15 de acordo com o estatuto posicional (defensores, meio-campistas e atacantes).

\section{Materiais e métodos}

\section{Amostra}

A amostra foi composta por 25 jogadores de futebol da categoria Sub-15 de dois clubes portugueses, os quais realizaram 1.410 ações táticas. Dessas ações, 492 foram realizadas por jogadores de defesa $(n=8), 487$ por jogadores de meio-campo $(n=9)$ e 431 por jogadores de ataque $(n=8)$. Como critério de inclusão da amostra, os jogadores deveriam estar inscritos em programas sistemáticos de treinamento, com no mínimo três sessões por semana, e competir, minimamente, em nível regional. Os jogadores e seus responsáveis foram esclarecidos sobre os objetivos e procedimentos do estudo e deram seu consentimento (Processo CEFADE $\left.\mathrm{n}^{\mathrm{o}} .15 / 2013\right)$.

\section{Instrumento de coleta de dados}

O instrumento utilizado para avaliar o comportamento tático dos jogadores foi o Sistema de Avaliação Tática no Futebol (FUT-SAT), validado por Teoldo et al. (2011a). O FUTSAT é composto por um teste de campo realizado em um campo reduzido de 36 metros de comprimento por 27 metros de largura, durante quatro minutos e as equipes são compostas por três jogadores e o goleiro $(\mathrm{GR}+3 \times 3+\mathrm{GR})$. Essa estrutura permite a ocorrência de todos os princípios táticos fundamentais do jogo de futebol (TEOLDO et al., 2009b). Durante o teste de campo, o comportamento tático dos jogadores é filmado para posterior análise baseada nos dez princípios táticos fundamentais do futebol (TEOLDO et al., 2009a). 


\section{Procedimento de coleta de dados}

A coleta de dados foi realizada em dois clubes portugueses, e as equipes que realizaram o teste GR+3x3+GR foram compostas de maneira que possuíssem um jogador de cada estatuto posicional (defesa, meio-campo e ataque). Os zagueiros e laterais foram categorizados como defensores; os volantes e meias compuseram o setor de meio-campo; e os centroavantes e atacantes foram categorizados como atacantes. Os jogadores receberam coletes numerados de um (1) a seis (6), com intuito de facilitar a posterior análise de vídeo. Antes do início efetivo do teste, houve uma explicação acerca dos procedimentos e, em seguida, foram concedidos 30 segundos de familiarização, ao fim dos quais se deu início à avaliação.

Para a gravação dos jogos foi utilizada uma câmera digital PANASONIC modelo NV - DS35EG. O material de vídeo gravado foi introduzido, em formato digital, num computador portátil (marca Positivo modelo Positivo Móbile, processador Intel Dual-Core) via cabo (IEEE 1394), e convertido em arquivos "avi". Para o tratamento das imagens e a análise do jogo, foram utilizados os softwares Soccer Analyser ${ }^{\circledR}$, específico para o teste do FUT-SAT, e Utilius $V S^{\circledR}$, destinado à análise das ações táticas e ao arquivamento dos jogos registrados.

\section{Análise Estatística}

Os dados foram tratados com o auxílio do software BioEstats 5.0 para Windows®. Foram realizadas as análises descritivas (frequência absoluta e relativa). Para a análise das variáveis nas categorias "Princípio Tático", "Localização da Ação no Campo de Jogo" e "Resultado da Ação", foi utilizado o teste Qui-quadrado $\left(\chi^{2}\right)$, por se tratar de dados categóricos. Em todos os casos o nível de significância adotado foi de $p<0,05$.

\section{Análise da confiabilidade}

Para verificar a confiabilidade intra e inter avaliadores, recorreu-se aos valores do teste Kappa de Cohen a partir do software SPSS (Statistical Package for Social Science) para Windows ${ }^{\circledR}$. Neste estudo, foi seguida a classificação apresentada por Landis e Koch (1977) e todos os três avaliadores participantes obtiveram resultado acima de 0,81 , considerado "quase perfeito". Foram reavaliadas 155 ações táticas, $11 \%$ da amostra, valor superior aos $10 \%$ recomendado pela literatura (TABACHNICK; FIDELL, 2001).

\section{Resultados}

\section{Princípios Táticos}

$\mathrm{Na}$ fase ofensiva, os defensores realizaram mais as movimentações que permitem à equipe atacar em unidade (Unidade Ofensiva) $\left(\chi^{2}=9,290 ; p=0,002\right.$ e $\left.\chi^{2}=8,397 ; p=0,004\right)$ em relação aos meio-campistas e atacantes, enquanto os meio-campistas realizaram mais as movimentações nas "costas" do último defensor adversário (Mobilidade) $\left(\chi^{2}=5,158 ; p=0,023\right)$ em relação aos defensores. Já na fase defensiva, os defensores realizaram mais as movimentações de oposição direta ao portador da bola (Contenção) $\left(\chi^{2}=4,642 ; p=0,031\right)$ e as que permitem à equipe proteger o gol e aumentar a pressão no centro de jogo (Concentração) $\left(\chi^{2}=4,056 ; p=0,044\right)$ em relação aos atacantes (Tabela 1). 
Tabela 1 - Frequência absoluta e relativa do total de ações táticas das variáveis da categoria Princípios Táticos em defensores, meio-campistas e atacantes

\begin{tabular}{|c|c|c|c|c|c|c|}
\hline \multirow{2}{*}{ Categorias e Variáveis } & \multicolumn{2}{|c|}{ Defensores } & \multicolumn{2}{|c|}{ Meio-campistas } & \multicolumn{2}{|c|}{ Atacantes } \\
\hline & $\mathbf{N}$ & $\%$ & $\mathbf{N}$ & $\%$ & $\mathbf{N}$ & $\%$ \\
\hline \multicolumn{7}{|l|}{ PRINCÍPIOS TÁTICOS } \\
\hline \multicolumn{7}{|l|}{$\underline{\text { Ofensivos }}$} \\
\hline Penetração & 30 & 6,1 & 33 & 6,8 & 31 & 7,2 \\
\hline Cobertura Ofensiva & 66 & 13,4 & 82 & 16,8 & 66 & 15,3 \\
\hline Espaço & 69 & 14,0 & 81 & 16,6 & 77 & 17,9 \\
\hline Mobilidade $^{a}$ & 12 & 2,4 & 26 & 5,3 & 22 & 5,1 \\
\hline Unidade Ofensiva $^{\mathrm{a}, \mathrm{b}}$ & 43 & 8,7 & 19 & 3,9 & 20 & 4,6 \\
\hline \multicolumn{7}{|l|}{$\underline{\text { Defensivos }}$} \\
\hline$\overline{\text { Contenção }}{ }^{b}$ & 58 & 11,8 & 45 & 9,2 & 37 & 8,6 \\
\hline Cobertura Defensiva & 18 & 3,7 & 20 & 4,1 & 21 & 4,9 \\
\hline Equilíbrio & 49 & 10,0 & 42 & 8,6 & 30 & 7,0 \\
\hline Concentração ${ }^{b}$ & 54 & 11,0 & 44 & 9,0 & 35 & 8,1 \\
\hline Unidade Defensiva & 93 & 18,9 & 95 & 19,5 & 92 & 21,3 \\
\hline TOTAL & 492 & 100,0 & 487 & 100,0 & 431 & 100,0 \\
\hline
\end{tabular}

Diferença Significativa (p<0,05): $a=$ Defensores x Meio-campistas; $b=$ Defensores $x$ Atacantes; $\mathrm{c}=$ Meio-campistas $\mathrm{x}$ Atacantes.

Fonte: Elaborada pelo autor, 2017.

Localização e Resultado da Ação

Os defensores $\left(\chi^{2}=7,642 ; p=0,006\right.$ e $\left.\chi^{2}=12,842 ; p<0,001\right)$ realizaram mais ações táticas ofensivas no meio de campo defensivo em relação aos meio-campistas e os atacantes. Adicionalmente, os meio-campistas $\left(\chi^{2}=8,067 ; p=0,005\right)$ e os atacantes $\left(\chi^{2}=6,231 ; p=0,013\right)$ cometeram mais falta, cederam mais laterais ou escanteio em relação aos defensores. Já os defensores continuaram mais sem a posse de bola $\left(\chi^{2}=3,910 ; p=0,048\right.$ e $\left.\chi^{2}=10,139 ; p=0,002\right)$ em relação aos meio-campistas e atacantes.

Tabela 2 - Frequência absoluta e relativa das variáveis das categorias Localização da Ação no Campo de Jogo e Resultado da Ação em defensores, meio-campistas e atacantes

\begin{tabular}{|c|c|c|c|c|c|c|}
\hline \multirow{2}{*}{ Categorias e Variáveis } & \multicolumn{2}{|c|}{ Defensores } & \multicolumn{2}{|c|}{ Meio-campistas } & \multicolumn{2}{|c|}{ Atacantes } \\
\hline & $\mathbf{N}$ & $\%$ & $\mathbf{N}$ & $\%$ & $\mathbf{N}$ & $\%$ \\
\hline \multicolumn{7}{|c|}{ LOCALIZAÇÃO DA AÇÃO NO CAMPO DE JOGO } \\
\hline \multicolumn{7}{|l|}{ Meio Campo Ofensivo } \\
\hline Ações Táticas Ofensivas & 125 & 25,4 & 146 & 30,0 & 127 & 29,5 \\
\hline Ações Táticas Defensivas & 9 & 19,3 & 95 & 19,5 & 89 & 20,6 \\
\hline \multicolumn{7}{|l|}{ Meio Campo Defensivo } \\
\hline$\overline{\text { Ações Táticas Ofensivas }}{ }^{\mathrm{a}} \mathrm{b}$ & 155 & 31,5 & 110 & 22,6 & 98 & 22,7 \\
\hline Ações Táticas Defensivas & 117 & 23,8 & 136 & 27,9 & 117 & 27,1 \\
\hline Total & 492 & 100,0 & 487 & 100,0 & 431 & 100,0 \\
\hline \multirow{2}{*}{\multicolumn{7}{|c|}{$\begin{array}{c}\text { RESULTADO DA AÇÃO } \\
\text { Ofensiva }\end{array}$}} \\
\hline & & & & & & \\
\hline Realizar finalização ao gol & 27 & 5,5 & 25 & 5,1 & 22 & 5,1 \\
\hline
\end{tabular}




\begin{tabular}{cllllll} 
Continuar com a posse de bola & 169 & 34,3 & 171 & 35,1 & 154 & 35,7 \\
Sofrer falta, ganhar lateral ou escanteio & 4 & 0,8 & 8 & 1,6 & 9 & 2,1 \\
Cometer falta, ceder lateral ou escanteio & 6 & 1,2 & 12 & 2,5 & 8 & 1,9 \\
Perder a posse de bola & 14 & 2,8 & 25 & 5,1 & 22 & 5,1 \\
$\quad$ Defensiva & & & & & & \\
Recuperar a posse de bola & 19 & 3,9 & 25 & 5,1 & 20 & 4,6 \\
Sofrer falta, ganhar lateral ou escanteio & 8 & 1,6 & 7 & 1,4 & 11 & 2,6 \\
Cometer falta, ceder lateral ou escanteio $^{\mathrm{a}, \mathrm{b}}$ & 2 & 0,4 & 13 & 2,7 & 11 & 2,6 \\
Continuar sem a posse de bola a,b & 214 & 43,5 & 175 & 35,9 & 153 & 35,5 \\
Sofrer finalização ao gol & 29 & 5,9 & 26 & 5,3 & 21 & 4,9 \\
$\quad$ Total & 492 & 100,0 & 487 & 100,0 & 431 & 100,0 \\
\hline
\end{tabular}

Diferença Significativa (p<0,05): a=Defensores x Meio-campistas; $b=$ Defensores x Atacantes; $\mathrm{c}=$ Meio-campistas x Atacantes.

Fonte: Elaborada pelo autor, 2017.

\section{Discussão}

O presente estudo teve como objetivo comparar o comportamento tático de jogadores de futebol da categoria Sub-15 de acordo com o estatuto posicional (defensores, meiocampistas e atacantes). Os resultados apontam que os defensores realizaram mais movimentações que permitem à equipe atacar em unidade em relação aos meio-campistas e atacantes. Além disso, os defensores realizaram mais movimentações de oposição direta ao portador da bola e de proteção à baliza nas zonas que permitem proteger o gol e aumentar a pressão no centro de jogo em relação aos atacantes. Por outro lado, os meio-campistas realizaram mais as movimentações nas "costas" do último defensor adversário em relação aos defensores.

Os resultados deste estudo não corroboram os encontrados por Gonzaga, Gonçalves e Teoldo (2014), os quais também investigaram jogadores de futebol da categoria Sub-15. Os referidos autores não encontraram diferenças no comportamento tático dos jogadores de acordo com o estatuto posicional, enquanto que os resultados deste estudo evidenciam comportamentos característicos da especialização dos jogadores na posição em que ocupam na equipe. Essa característica de especialização pode ser observada, pois, conforme aponta a literatura, as movimentações atrás da linha da bola e fora do centro de jogo (durante a fase ofensiva) são características de compactação da linha defensiva com a de meio de campo e permitem à equipe atacar como um todo (SAMPAIO et al., 2013). Dessa maneira, essas movimentações tendem a ser realizadas com mais frequência pelos defensores, devido a seus posicionamentos no campo de jogo. Portanto, uma possível explicação para a divergência entre os resultados deste estudo e o de Gonzaga, Gonçalves e Teoldo (2014) pode estar nas características das concepções de jogo dos processos de formação de jovens jogadores de futebol de Portugal e do Brasil, países em que as duas pesquisas foram realizadas.

Por conseguinte, as movimentações de oposição direta ao portador da bola e de proteção à baliza nas zonas que permitem proteger o gol e aumentar a pressão no centro de jogo (fase defensiva) são fundamentais para impedir as ações ofensivas dos adversários e proporcionar uma possível retomada da posse da bola (GREHAIGNE; BOUTHIER; DAVID, 1997). Essas movimentações também corroboram o fato de o comportamento dos jogadores apresentar características das posições que exercem no campo de jogo, pois a literatura aponta que essas movimentações, quando bem desempenhadas pelos jogadores, tendem a gerar uma compactação na equipe, a qual pode gerar uma organização defensiva eficiente (GRÉHAIGNE; GODBOUT; ZERAI, 2011). Portanto, essas movimentações tendem a ser realizadas com mais proficiência pelos defensores em detrimento das demais posições, pois 
necessitam ocupar um setor do campo onde a não realização bem sucedida dessas movimentações pode gerar um risco de gol à própria equipe (GREHAIGNE; BOUTHIER; DAVID, 1997; GIACOMINI; GRECO, 2008).

Adicionalmente, os defensores realizaram mais movimentações ofensivas no meio de campo defensivo e demonstraram, em relação aos meio-campistas e os atacantes, maior capacidade de não cometer falta e ceder lateral ou escanteio. Esses resultados confirmam que os defensores possuem mais proficiência relacionada à sua posição que os jogadores das demais posições, provavelmente devido à aquisição de experiência através dos treinamentos e os jogos (SAMULSKI, 2009; GIACOMINI; GRECO, 2008). Em consonância a isso, Kannekens, Elferink-Gemser e Visscher (2009) preconizam que a maior experiência em treinamentos, competições e jogos considerados relevantes gera melhor desempenho esportivo para os jogadores e as equipes. Assim, durante o processo de ensino-aprendizagem e treinamento, devemse considerar as especificidades das posições dos jogadores, para que sejam capazes de cumprir suas dinâmicas táticas durante o jogo.

Ademais, a realização de movimentações fora do centro de jogo pode ter favorecido a não fragmentação do jogo e pode ter permitido que os defensores continuassem mais sem a posse de bola, pois as ações fora do centro de jogo não têm interferência direta nas ações do portador da bola (TEOLDO et al., 2009a). Além disso, outro fator que pode explicar esse resultado é a relação entre o número de jogadores e a dimensão do campo, pois, quanto maior a área de atuação dos jogadores no campo de jogo, maior é a possibilidade de uma equipe manter a posse de bola (VILAR; DUARTE; SILVA, 2014; SILVA et al., 2015). Portanto, o resultado desta pesquisa corrobora os achados de Teoldo et al. (2011b), os quais demonstraram que, no jogo com campo reduzido de 36 metros de comprimento por 27 metros de largura, as equipes tiveram mais dificuldade de recuperar a posse de bola em relação ao jogo realizado em um campo com dimensões menores que a utilizada por este estudo, que também foi de 36 metros de comprimento por 27 metros de largura.

Por sua vez, as movimentações nas "costas" do último defensor adversário foram as menos frequentes entre os defensores, provavelmente devido à atuação mais característica no meio de campo defensivo, longe da linha de fundo adversária. Esse aspecto está em consonância com a especialização na posição pelos jogadores de defesa referida anteriormente. No entanto, as exigências do futebol moderno requerem que os jogadores realizem ações que vão além das movimentações mais características de cada posição (GARGANTA, 1997; TEOLDO; GUILHERME; GARGANTA, 2015). Portanto, os treinadores de futebol devem explorar as ações, como as movimentações nas "costas" do último defensor adversário, para que os defensores aumentem seu repertório de ações e, consequentemente, sua experiência no campo de jogo. Dessa maneira, os jogadores tenderão a responder melhor às exigências do jogo, independentemente da posição ocupada pelo jogador nas situações de jogo.

Por outro lado, a maior frequência das movimentações nas "costas" do último defensor adversário por parte dos meio-campistas, em relação aos defensores, indica que os meiocampistas atuaram mais próximo à baliza adversária. Isso pode ter ocorrido porque os atacantes, provavelmente, participaram mais ativamente das ações de construção do jogo (portando a bola ou dentro do centro de jogo), enquanto que os meio-campistas procuraram criar espaços na defesa adversária para que a bola pudesse ser passada para o jogador com melhor posicionamento (GRÉHAIGNE; GODBOUT; ZERAI, 2011). Além disso, os atacantes podem ter procurado jogar de maneira mais objetiva, na busca por finalizar a baliza adversária, tendendo a agir mais próximo ao centro de jogo (AMARAL; GARGANTA, 2005).

Em relação às ações de construção do jogo, o estudo de Giacomini e Greco (2008) comprova que os meio-campistas possuem maiores valores descritivos de conhecimento tático processual (divergente), seguidos dos atacantes. Os autores supracitados preconizam que esse conhecimento está relacionado com a criatividade dos jogadores e afirmam que os meio- 
campistas podem ter esse conhecimento desenvolvido devido às zonas do campo em que desempenha a maior parte de suas ações, nas quais necessitam ter criatividade para dar sequência às jogadas em ações com ou sem bola. Os autores afirmam ainda que os defensores desempenham suas ações em zonas do campo onde a "simplificação" da jogada apresenta-se mais adequada para que a equipe não corra o risco de sofrer finalizações a própria baliza, prejudicando a manifestação do pensamento divergente.

Portanto, no processo de ensino-aprendizagem e treinamento do futebol, as características das posições dos jogadores devem ser consideradas para o planejamento e execução dos exercícios. No entanto, de acordo com Garganta et al. (2013), para cumprir as exigências do futebol moderno, importa que esse processo possibilite estimular o desenvolvimento dos jogadores para as competências situacionais e adaptativas. Em outras palavras, os autores preconizam que é necessário desenvolver os conhecimentos e as competências que assegurem que os jogadores possam agir nas diferentes fases e momentos do jogo, em função das possibilidades de ação que se criam e que emergem nas diferentes situações de jogo.

Em termos de aplicação prática, este estudo demonstra que o estatuto posicional influenciou a realização dos comportamentos dos jogadores expressos por suas ações táticas, assim como a localização e o resultado dessas ações, sobretudo no que se refere aos defensores. Portanto, este estudo revela a importância de direcionar os treinamentos às características de cada posição para promover os comportamentos necessários à equipe. Além disso, é relevante incorporar conteúdos que se relacionem às movimentações ofensivas para que os defensores possam realizar ações de construção do jogo em seu próprio campo, assim como trabalhar com os conteúdos inerentes à fase defensiva, a fim de que os jogadores de meio-campo e ataque possam ter a competência de, principalmente, recuperar a posse de bola no intuito de gerar vantagens à equipe.

Em última análise, apesar da contribuição desse estudo para a compreensão de como os jogadores de futebol de diferentes posições se comportam, além da contribuição prática que pode auxiliar os treinadores no planejamento e execução dos exercícios durante os treinamentos, algumas limitações foram encontradas. Dentre essas limitações, não foram investigadas as características do processo de formação esportiva em Portugal, sobretudo em relação às concepções de jogo dos clubes analisados. Além disso, não foram investigados os conteúdos ensinados no processo de formação desses jovens jogadores. Tais informações poderiam auxiliar no entendimento se, de fato, as características de especialização nas posições são decorrentes do processo de ensino e treino ou da demanda específica da tarefa realizada pelos jogadores na situação de jogos reduzidos e condicionados.

\section{Conclusão}

Conclui-se que o comportamento dos jogadores expressos pelas ações táticas apresentou padrões específicos das posições que os jogadores exercem no campo de jogo, indicando especialização nas respectivas posições. Com isso, os professores e treinadores podem avaliar os jogadores e, com base nos seus comportamentos, determinar as posições mais adequadas para os jogadores. Além disso, podem desenvolver treinamentos, com o intuito de superar as limitações na realização de comportamentos relacionados às demais posições e, assim, desenvolver as potencialidades dos jogadores para melhoria de rendimento. Sugere-se, portanto, que novas investigações sejam realizadas para aumentar a compreensão de como os jogadores de futebol se comportam em função do estatuto posicional, propondo estudos que realizem avaliações em um processo de treinamento em longo prazo e investigando a interferência do treino sobre o aprendizado do jogador. 


\section{Agradecimentos}

Este trabalho teve o apoio da FAPEMIG, da SEESP-MG através da LIE, da CAPES, do CNPq, da FUNARBE, da Reitoria, Pró-Reitoria de Pesquisa e Pós-Graduação e do Centro de Ciências Biológicas e da Saúde da Universidade Federal de Viçosa.

\section{Referências}

AMARAL, R.; GARGANTA, J. A modelação do jogo em Futsal. Análise sequencial do 1x1 no processo ofensivo. Revista Portuguesa de Ciências do Desporto, v. 3, n. 5, p. 298-310, 2005.

BAYER, C. O ensino dos desportos colectivos. Lisboa: Dinalivro, 1994.

DI SALVO, V. et al. Performance characteristics according to playing position in elite soccer. International Journal of Sports Medicine, v. 28, n. 3, p. 222-227, 2007.

GARGANTA, J. Modelação táctica do jogo de futebol: estudo da organização da fase ofensiva em equipas de alto rendimento. 1997. 292f. Tese (Doutorado em Ciência do Desporto) Faculdade de Ciências do Desporto e de Educação Física, Universidade do Porto, Porto, 1997.

GARGANTA, J.; GRÉHAIGNE, J. F. Abordagem sistêmica do jogo de futebol: moda ou necessidade? Movimento, v. 5, n. 10, p. 40-50, 1999.

GARGANTA, J. et al. Fundamentos e prática para o ensino e treino do futebol. In: TAVARES, F. (Ed.). Jogos desportivos coletivos: ensinar a jogar. Porto: Faculdade de Desporto da Universidade do Porto; Centro de Estudos dos Jogos Desportivos, 2013. p. 199-263.

GIACOMINI, D. S.; GRECO, P. J. Comparação do conhecimento tático processual em jogadores de futebol de diferentes categorias e posições. Revista Portuguesa de Ciência do Desporto, v. 8, n. 1, p. 126-136, 2008.

GONÇALVES, E.; REZENDE, A. L. G.; TEOLDO, I. Comparação entre a performance tática defensiva e ofensiva de jogadores de futebol Sub-17 de diferentes posições. Revista Brasileira de Ciências do Esporte, v. 1, n. 1, p. 1-10, 2015.

GONZAGA, A. S.; GONÇALVES, E.; TEOLDO, I. Comparação do comportamento tático de jogadores de futebol da categoria sub-15 de diferentes posições. Revista Brasileira de Futebol, v. 6, n. 2, p. 52-59, 2014.

GREHAIGNE, J.; BOUTHIER, D.; DAVID, B. Dynamic-system analysis of opponent relationships in collective actions in soccer. Journal of Sports Sciences, v. 2, n. 15, p. 137-149, 1997.

GRÉHAIGNE, J. F.; GODBOUT, P.; ZERAI, Z. How the "rapport de forces" evolves in a soccer match: The dynamics of collective decisions in a complex system. Revista de Psicologia del Deporte, v. 20, n. 2, p. 747-765, 2011.

JAMES, N.; MELLALIEU, S. D.; HOLLELY, C. Analysis of strategies in soccer as a func- 
tion of European and domestic competition. International Journal of Performance Analysis in Sport, v. 2, n. 1, p. 85-103, 2002.

KANNEKENS, R.; ELFERINK-GEMSER, M. T.; VISSCHER, C. Tactical skills of worldclass youth soccer teams. Journal of Sports Sciences, v. 27, n. 8, p. 807-812, 2009.

LANDIS, J. R.; KOCH, G. G. The measurement of observer agreement for categorical data. Biometrics, v. 33, n. 1, p. 159-174, 1977.

PADILHA, M. B.; MORAES, J.; TEOLDO, I. O estatuto posicional pode influenciar o desempenho tático ente jogadores da Categoria Sub-13? Revista Brasileira de Ciência e Movimento, v. 21, n. 4, p. 73-79, 2013.

SAMPAIO, J. E. et al. Effects of pacing, status and unbalance in time motion variables, heart rate and tactical behaviour when playing 5-a-side football small-sided games. Journal of Science and Medicine in Sport, v. 17, n. 2, p. 229-233, 2013.

SAMULSKI, D. Regulação psicológica da ação esportiva. In: SAMULSKI, D. (Ed.). Psicologia do esporte: conceitos e novas perspectivas. 2. ed. Barueri, SP: Manole, 2009. p. 496.

SANTOS, R. et al. A superfície de jogo pode influenciar o desempenho tátio de jogadores de futebol? Revista da Educação Física/UEM, v. 24, n. 2, p. 247-252, 2013.

SILVA, B. et al. Comparing Tactical Behaviour of Soccer Players in 3 vs. 3 and 6 vs. 6 Small-Sided Games. Journal of Human Kinetics, v. 41, n. 1, p. 191-202, 2014.

SILVA, P. et al. Effects of manipulations of player numbers vs. field dimensions on interindividual coordination during small-sided games in youth football. International Journal of Performance Analysis in Sport, v. 15, n. 1, p. 641-659, 2015.

TABACHNICK, B.; FIDELL, L. Using multivariate statistics: international edition. 6. ed. London: Pearson Education, 2001.

TAYLOR, J. B.; MELLALIEU, S. D.; JAMES, N. A comparison of individual and unit tactical behaviour and team strategy in professional soccer. International Journal of Performance Analysis in Sport, v. 5, n. 2, p. 87-101, 2005.

TEOLDO, I. et al. Influência de tipo de piso, dimensão das balizas e tempo de jogo na aplicação do teste de "GR3-3GR" em futebol. Revista Lecturas em Educación Física y Deportes, v. 14, n. 136, p. 1-10, $2009 \mathrm{~b}$.

Princípios táticos do jogo de futebol : conceitos e aplicação. Motriz, v. 15, n. 3, p. 657-668, 2009a.

TEOLDO, I.et al. Relação entre a dimensão do campo de jogo e os comportamentos táticos do jogador de futebol. Revista Brasileira de Educação Física e Esporte, v. 25, n. 1, p. 79-96, $2011 b$.

TEOLDO, I.;et al. System of tactical assessment in soccer (FUT-SAT): development and preliminary validation. Motricidade, v. 7, n. 1, p. 69-83, $2011 \mathrm{a}$. 
TEOLDO, I.; GUILHERME, J.; GARGANTA, J. Para um futebol jogado com ideias: concepção, treinamento e avaliação do desempenho tático de jogadores e equipes. Curitiba: Appris, 2015.

VILAR, L.; DUARTE, R.; SILVA, P. The influence of pitch dimensions on performance during small-sided and conditioned soccer games. Journal of Sports Sciences, v. 32, n. 19, p. 1751-1759, 2014.

Recebido em: 23/11/2017

Revisado em: 16/02/2018

Aprovado em: 22/02/2018

Endereço para correspondência:

davizirt@hotmail.com

Davi Correia da Silva

Universidade Federal de Viçosa

Avenida Peter Henry Rolfs, $s / n$

Campus Universitário, Viçosa - MG, 36570-900 